Voix et Images

voixetimages

\title{
Langagement (1960-1975)
}

\section{André Major}

Volume 1, numéro 1, septembre 1975

\section{Hubert Aquin}

URI : https://id.erudit.org/iderudit/013990ar

DOI : https://doi.org/10.7202/013990ar

Aller au sommaire du numéro

\section{Éditeur(s)}

Les Presses de l'Université du Québec

\section{ISSN}

0318-9201 (imprimé)

1705-933X (numérique)

Découvrir la revue

\section{Citer cet article}

Major, A. (1975). Langagement (1960-1975). Voix et Images, 1(1), 120-124.

https://doi.org/10.7202/013990ar d'utilisation que vous pouvez consulter en ligne.

https://apropos.erudit.org/fr/usagers/politique-dutilisation/ 


\section{Langagement (1960-1975)}

NDLR. "Langagement " reprend ici l'essentiel d'une conférence donnée à I'Université du Québec à Rimouski à l'invitation du département des Lettres et des Sciences humaines, le 6 avril 1975. Notre collaborateur venaii alors de publier l'Épidémie (aux Éditions du Jour), suite de l'Épouvantail, roman paru en 1974.

Remontons au début des années 60, alors qu'encore adolescent j'avais vu mourir Duplessis sans que le duplessisme soit enterré du même coup, et voyons ce qui se passait, pas grand-chose, quand j'y pense, sinon que j'écrivais mes premiers romans durant les cours dont j'avais horreur, mais étaient-ce vraiment des romans, ces imitations de Bernanos, ces maladroites gesticulations de révolté impuissant à diagnostiquer son mal, vaguement conscient d'être en désaccord avec la famille, le collège et le pays, aux prises avec le Désir et ne s'en libérant qu'après d'interminables débats de conscience, sans l'aide de personne. $A$ bien y penser, en marge de la médiocrité ambiante, il y avait matière à se passionner puisque le Livre de poche me donnait Gide, Malraux, Camus, Kafka, Koestler, avant Sartre qui fut le grand inspirateur des années qui suivirent. II y avait aussi Laurendeau et le Frère Untel, le Journal d'un Inquisiteur et la rencontre de Gaston Miron un peu plus tard, et celle de Jacques Ferron, membre tout comme moi de l'Action socialiste pour l'indépendance du Québec, mouvement où pour la première fois le socialisme ouvrait les bras au nationalisme pour baptiser l'enfant de ce mariage du nom de décolonisation, notion que Memmi et Fanon allaient nous permettre de développer à notre façon par la suite quand Parti pris prendrait la relève de Cité libre dont la pensée réformiste allait subir maintes distorsions, une fois mise à l'épreuve du pouvoir.

Mais en 60,61 et 62 , les choses traînaient, et si j'étais libéré des études, par ma très grande faute, après avoir diffusé un journal local surtout dirigé contre ce que j'appellerais le duplessisme intellectuel, je faisais tout et rien, suivant des cours de journalisme, lisant n'importe quoi avec le beau désordre de l'autodidacte en quête de connaissances acquises sans la moindre méthode, discutant dans ces cafés où le jazz et la poésie constituaient un décor, un climat, j'allais dire un apprentissage ayant ses 
règles propres, comme le port du chandail à col roulé et du pantalon de velours côtelé sans quoi on risquait de demeurer étranger au milieu. Toute cette bohème n'allait pas loin: elle finissait généralement dans un lit avec une couventine en chaleur. Encore fallait-il avoir surmonté un puritanisme que pour ma part je rejetais sans parvenir à m'en dégager véritablement si bien que je rentrais chez moi, la rage au cœur et la queue basse. Je ne sais pas si cette frustration pourrait expliquer le besoin de violence qui me poussait à refaire le maquillage des grands personnages qui avaient présidé à la création de la Confédération. Mais je crois qu'il y avait déjà chez moi, avant même que Sartre dénonce l'exercice de la littérature comme activité sacrée ou absolue, le sentiment d'avoir à agir sur l'Histoire, non seulement par des moyens intellectuels mais par tous les moyens, à rebours de tout l'humanisme dans lequel les études classiques m'avaient plongé. Ce besoin d'agir était dans l'air, il faut croire, puisqu'au moment où paraissaiit un article que j'avais écrit après la lecture de Nizan, et que j'avais témérairement intitulé “les Armes à la main», les bombes se mettaient à sauter à Montréal. Panique générale, têtes mises à prix et tout le branle-bas. Tout à coup le Québec devenait un problème. Le premier ministre Lesage profitait de ce vacarme pour donner un peu de poids à une Révolution qu'il craignait de ne plus être aussi tranquille qu'elle prétendait l'être. II nous semblait urgent, dès ce moment, de mener un combat sur trois fronts: celui des institutions qu'il s'agissait de laïciser et de démocratiser, chose faite à la hâte et plus ou moins réussie, celui de l'ordre socio-économique qu'il importait d'orienter dans le sens de la justice, c'est-à-dire du socialisme, et aussi celui d'une conscience nationale encore sourde à ses exigences historiques. Bref, le groụpe qui devait publier Parti pris en automne 63 entendait travailler à la construction d'un État laïque, socialiste et indépendant. II fallait commencer par analyser la situation globale du Québec, ce qui devait se faire dans la perspective de ce que nous appelions le combat décolonisateur. L'idéologie qui s'est développée au cours de ces années, et bien que dès 64 je fusse disparu de la circulation, me semble encore aujourd'hui d'une terrible actualité. Je dis terrible parce que l'évolution du Québec n'a pas rendu caduque cette idéologie, même s'il existe une opposition organisée. Cette opposition, qui a forcément des visées électorales, nous dore la pilule. C'est peut-être inévitable. Mais le problème québécois demeure entier.

Revenons en arrière pour voir un peu clair dans le paysage idéologique de ces années: complètement dépassé sur sa gauche, Cité libre s'est fait hara-kiri en courant après le pouvoir, moins pour changer la société que pour maintenir ses structures traditionnelles, c'est-à-dire la démocratie libérale telle qu'elle s'incarne dans la Confédération canadienne. Incapables de faire face à la montée souverainiste, d'y faire face intellectuellement, les disciples de Mounier ont simplement pris la relève des Laurier et Pearson, témoignant ainsi de leur total manque de foi en nousmêmes. A ce moment-là, les intellectuels avaient le beau rôle, après avoir maudit le duplessime, puisqu'ils formaient une sorte d'avant-garde d'autant plus influente qu'ils étaient les seuls porte-parole de la communauté, que 
ce soit pour la maintenir dans le statu quo ou l'en libérer. Ils parlaient, et on les écoutait, non pas par respect mais parce qu'ils disaient quelque chose. Toute la pensée de Parti pris, par exemple, s'est diffusée, a rayonné à tel point que, dix ans plus tard, son vocabulaire faisait partie du décor québécois. II faut être sacrement bouché des deux bouts pour nier aujourd'hui l'état quasi colonial où se trouve le Québec. Parti pris, en ce sens, a été plus qu'un simple instrument de politisation; ç'a été un mouvement idéologique qui a influencé notre conception de la culture. On pourrait dire que le "Maîtres chez nous " du gouvernement Lesage correspondait, chez les écrivains qui gravitaient autour de Parti pris, à une volonté de comprendre, d'exprimer et de libérer l'homme québécois, préoccupation nouvelle dont la poésie a été le véhicule privilégié. C'est Franz Fanon qui dit que «de réplique mineure du dominateur qu'elle était, la production autochtone se différencie et se fait volonté particularisante". L'époque où l'écrivain québécois emboîtait le pas de l'écrivain français était révolue. Conscient d'être aussi aliéné que ses compatriotes, l'écrivain québécois entendait réfléchir cette situation et cesser de l'escamoter. C'est ainsi qu'il s'est posé le problème du langage, et une nouvelle prose s'est créée, une prose à la fois réaliste et contestataire, proche du quotidien sans pourtant se limiter à le reproduire puisque toute création suppose que l'artiste s'ajoute à ce qu'il décrit. Dans la mesure où il était conscient d'être aliéné, l'écrivain qui refusait la fuite se rendait compte que son destin était solidaire du destin collectif, ce qui l'amenait à travailler à partir de la réalité nationale. Son rôle consistait donc à montrer cette réalité telle qu'il la percevait, telle qu'il l'éprouvait, quitte à récuser la notion même d'œuvre littéraire. On se souvient du pathétique L'afficheur hurle de Chamberland et des réticences de Miron à rapailler ses morceaux choisis. Cette attitude s'explique par le sentiment d'urgence qui prévalait à un moment où l'intellectuel ne se sentait pas épaulé par un mouvement populaire, réduit à être une sorte de porte-parole marginal. Mais vers 68, Parti pris a disparu avec le RIN, comme pour permettre au Parti québécois de se manifester. Rassemblement de diverses tendances, le Parti québécois devenait le véritable véhicule du combat décolonisateur, reléguant du même coup les intellectuels à un rôle de second plan. C'était une étape normale et même souhaitable parce qu'enfin on passait d'un groupe de pression à une organisation partisane, susceptible non seulement de diffuser davantage l'idéologie souverainiste mais de menacer le pouvoir sur le terrain politique.

Il y a eu démobilisation à partir de ce moment-là. Se sentant de trop, les intellectuels ont pris leur trou, comme on dit, ce qui a permis à certains de découvrir les vertus orientales et à d'autres de prendre des vacances. Si Parti pris avait constitué une opposition intellectuelle au régime on ne peut pas dire que le Parti québécois a joué ce rôle. II avait d'autres tâches à remplir: s'organiser et jouer le jeu. II fallait le faire. Mais ce n'était pas une raison pour que disparaisse tout examen critique, toute recherche idéologique. La Crise d'octobre n'a rien fait pour arranger les choses. Le climat de terreur et de répression semble au contraire avoir 
favorisé la mise à la retraite prématurée de la plupart de nos intellectuels. Vous allez me dire qu'on n'a peut-être pas besoin de ces gens-là pour avancer. J'ai envie de dire une énormité et je vais la dire: à cause du silence des intellectuels québécois, on est actuellement en pleine confusion mentale. Exemple: faute d'exercer le pouvoir, nous cherchons dans l'originalité culturelle une identité que nous fournirait normalement l'exercice de notre souveraineté. Faute de prendre le pouvoir, nous nous imaginons avoir inventé une langue, appelez-la jouale ou québécoise, ça ne change rien. Faute de prendre le pouvoir, nous regardons le moindre objet patenté par nos ancêtres avec des yeux ronds comme des trente sous. Nous pataugeons dans le pittoresque et la folklorisation. C'est la raison pour laquelle nous avons besoin de nous faire dire par un achalant d'intellectuel: attention, si on a raison de revendiquer le passé culturel, de réhabiliter la culture nationale pour justifier l'avenir de cette culture, il ne faut pas s'arrêter là et s'y complaire. La culture ce n'est pas seulement l'acquis, c'est le travail d'aujourd'hui, c'est le présent, c'est le combat quotidien de tout un peuple. Sinon on folklorise une culture, on la condarnne à l'étouffement même si c'est dans un musée en bois de grange.

Parti pris ne valorisait pas le joual; il s'en servait pour dénoncer une situation précise: d'une part l'irréalisme malsain d'une certaine littérature, et d'autre part l'aliénation culturelle du Québécois. Maintenant, au nom d'une authenticité plutôt douteuse, on valorise ce patois de la misère, ce bégaiement de dépossédé, comme si avec le temps c'était devenu un langage libéré. A moins de vouloir enfermer l'homme québécois dans sa condition, on ne peut voir dans le joual autre chose qu'un indice extrêmement significatif de sa déculturation, de la violence que lui fait la culture dominante. Bien sûr, si vous allez au théâtre, et qu'on vous propose une description exacte de la réalité québécoise, vous reconnaîtrez dans l'accent, dans le ton, dans les mots eux-mêmes ce que vous êtes peu ou prou. Là n'est pas la question. Entre la description inévitable de la situation où nous croupissons encore et sa glorification, il y a place pour une perspective critique parfois terriblement absente de nos débats.

II faut comprendre que le créateur part du présent, et ce présent est joual, c'est-à-dire aliénant, ce qui ne signifie pas qu'on doive s'en accommoder comme on le fait, encore moins en déduire une idéologie folklorisante. Dans la lutte pour la dure reconquête de soi, le colonisé est amené à revendiquer tout son passé, à faire l'éloge de tout ce dont on lui faisait honte. II doit même passer par là pour retrouver une dignité perdue et qui lui est nécessaire pour s'accepter tel qu'il est. Mais cela fait, une autre tâche l'attend, plus exigeante encore, plus contradictoire aussi: réévaluer son passé en fonction de ses besoins, rejeter ce qui peut entraver sa libération et s'affirmer sans avoir recours à ces valeurs-refuge que constituent pour le moment les diverses contrefaçons d'une identité qui lui échappera aussi longtemps qu'il ne sera pas le véritable artisan de son destin. Nous en sommes à nous flatter la bedaine avec un plaisir adolescent, à nous dire que nous sommes aussi fins et beaux que n'im- 
porte qui, à nous faire accroire que nous valons mieux que les Français et les Américains ensemble, comme si nous avions besoin de ce complexe de supériorité pour entreprendre la longue marche vers l'avenir. Maintenant que nous avons foi en nous-mêmes, à tel point d'ailleurs que ceux qui nous exploitent misent sur ce sentiment - même la publicité nous dit que quand on est québécois on est fier de son choix -, maintenant que le miroir ne nous fait plus peur, il serait peut-être temps de regarder ailleurs, vers ce pouvoir qui appartient toujours aux autres, ce qui rend tout à fait illusoire la certitude que nous pouvons avoir d'être dégagés de la responsabilité de nous battre.

Quant à l'écrivain, il doit se demander s'il n'est pas en train de radoter quand il écrit, s'il montre avec suffisamment d'efficacité cette réalité qu'il est si facile et si tentant de maquiller pour ne pas avoir à la dénoncer. Et quand je dis dénoncer, je ne dis pas en termes politiques explicites. Je veux dire simplement: avec toute la rigueur et la vérité dont il est capable. Déclassé, considéré comme producteur marginal, l'écrivain n'est rien de plus mais rien de moins qu'un homme de langage, mais le langage c'est ce par quoi tout peut changer si, comme le dit Sartre, "nommer c'est montrer, et montrer c'est changer». Ici, l'écrivain n'exerce pas un métier, il écrit comme d'autres s'occupent d'un comité de citoyens ou font de la motoneige, ce qui revient à dire qu'il ne produit pas pour assurer son bien-être matériel mais pour répondre à ce qu'il faut bien appeler une exigence spirituelle. Cette exigence, il me semble que Sartre - encore lui la définit lumineusement: "récupérer ce monde-ci en le donnant à voir tel qu'il est, mais comme s'il avait sa source dans la liberté humaine". Conception de l'écriture beaucoup plus large qu'on l'a dit parce que si elle ne fait pas de l'écrivain un militant exemplaire, elle en fait un artisan conscient d'œuvrer dans le vif de l'humain.

C'est peut-être une chose que nous découvrons lentement: le dynamiste de la création, manifestation de liberté en faveur de la liberté. Mais s'il est avant tout préoccupé de libérer le langage, l'écrivain demeure un citoyen sans privilège de caste, et à ce titre il est également préoccupé de la libération de la communauté dont le sort est solidaire du sien, surtout si celle-ci est particulièrement menacée. Il faut cependant avoir le courage d'en convenir: pour les gouvernements que nous avons, l'intellectuel n'est pas une nuisance publique, il n'existe même pas. II ne saurait donc compter sur ses interventions pour les talonner, leur mettre la puce à l'oreille, les inquiéter un peu. Mais ceci ne devrait pas empêcher l'écrivain de s'adresser à qui de droit, c'est-à-dire à son public. 